Volume 7

Issue 4 -- Women and Cancer

Article 1

$10-23-2020$

\title{
Action Items for Breast Cancer Awareness Month
}

Deanna J. Attai

Follow this and additional works at: https://aah.org/jpcrr

Part of the Community Health and Preventive Medicine Commons, Health Services Research Commons, Neoplasms Commons, Oncology Commons, Public Health Education and Promotion Commons, Surgery Commons, Translational Medical Research Commons, and the Women's Health Commons

\section{Recommended Citation}

Attai DJ. Action items for Breast Cancer Awareness Month. J Patient Cent Res Rev. 2020;7:291-4. doi: 10.17294/2330-0698.1801

Published quarterly by Midwest-based health system Advocate Aurora Health and indexed in PubMed Central, the Journal of Patient-Centered Research and Reviews (JPCRR) is an open access, peer-reviewed medical journal focused on disseminating scholarly works devoted to improving patient-centered care practices, health outcomes, and the patient experience. 


\title{
Action Items for Breast Cancer Awareness Month
}

\author{
Deanna J. Attai, MD | Issue Editor (Women and Cancer) \\ Department of Surgery, David Geffen School of Medicine at UCLA, Los Angeles, CA
}

October is Breast Cancer Awareness Month (BCAM) in many countries, and it's hard to miss it. Pink merchandise floods the stores, all types of products are labeled with pink ribbons, and countless stories are told of women who have "beat" breast cancer. Often, the messaging is focused on early detection and the importance of screening mammograms.

This special issue of the Journal of Patient-Centered Research and Reviews is dedicated to the theme "Women and Cancer." In addition to containing original research on uterine cancer, hysterectomy, and pain relief during labor, ${ }^{1-3}$ several articles published within this issue pertain to predicting treatment outcomes, improving quality of life, and gleaning the patient perspective of those affected by breast cancer. ${ }^{4-8}$ These impactful studies are the kind that demand further support, both in terms of patient participation and research funding, and it's time for awareness campaigns to drive the public toward such new and promising goals.

Herein, we briefly describe the origination of marketing campaigns aimed at increasing breast cancer awareness and how these campaigns could be updated to avoid losing relevance to a present-day public already educated on the importance of screening.

\section{History of the Pink Ribbon}

The pink ribbon that has adorned everything from National Football League player uniforms to bags of pet food actually started off as a peach-colored ribbon. The message that Charlotte Haley wanted to send in 1992 was one of lack of research funding for cancer prevention. When she declined to allow her ribbon to be used for a magazine marketing

Corresponding author: Deanna J. Attai, MD, UCLA Health Burbank Breast Care, 191 S. Buena Vista, \#415, Burbank, CA 91505 (dattai@mednet.ucla.edu) campaign, a pink ribbon was used instead. ${ }^{910}$ Since that time, breast cancer advocacy organizations are often distinguished by pink logos and use the ribbon in their educational and marketing materials. Many wear pink to signify their struggles with the disease or to show support for a loved one who has been treated for breast cancer.

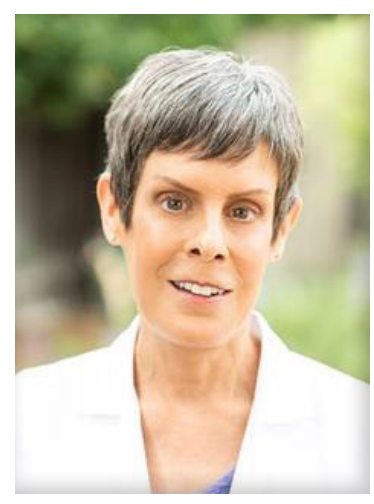

However, the pink ribbons are not always appreciated. Some people with breast cancer do not feel comfortable being "branded" or identified by their medical condition, and many patients do not identify with the term "survivor," 11 which is often used in BCAM campaigns. Men and the impact of male breast cancer are often left out of BCAM messaging. In addition, concerns have been raised regarding "pinkwashing," when a pink ribbon and inspiring slogan are placed on a product with a message of awareness, even though no proceeds from the sale of the product actually go toward breast cancer education, detection, or research. ${ }^{12}$

The reality of breast cancer is that the patient experience does not always fit neatly into a positive or inspirational marketing campaign. Efforts to raise awareness of breast cancer risk factors, benefits of screening, and treatment options remain necessary. However, there are important aspects of breast cancer not being addressed at many of the attention-grabbing pink ribbon events, including metastatic breast cancer, male breast cancer, and racial and ethnic disparities related to diagnosis, treatment, and outcomes. Thus the question is raised: Is spreading awareness enough, and do existing advocacy campaigns accurately reflect the many faces of breast cancer?

\section{Metastatic Breast Cancer}

The traditional messaging that "early detection saves lives" does not always hold true - early detection is 
important, but it is not the only factor that impacts survival. Metastatic breast cancer occurs when the original tumor has spread beyond the breast and regional lymph nodes, most commonly to the lungs, liver, bone, and brain..$^{13}$ It is estimated that there are approximately 150,000 women in the United States currently living with metastatic breast cancer. However, U.S. registries do not routinely collect or report recurrence data, so more precise figures are not available. ${ }^{14,15}$ Metastases are more likely to occur in the setting of higher stage at diagnosis or aggressive tumor biology but can occur even in those diagnosed with early stage, slower growing tumors, including after a long disease-free interval. Approximately $6 \%$ of all newly diagnosed breast cancers are de novo metastatic, meaning they are metastatic at the time of diagnosis. ${ }^{16}$ The American Cancer Society estimates that approximately 41,000 women and 500 men in the United States will die this year due to breast cancer, ${ }^{16}$ with most of these deaths caused by metastatic breast cancer. Death from breast cancer certainly does not fit into the "survivor" narrative, and patients with metastatic breast cancer are often left out of awareness campaigns. In 2009, the U.S. Congress did designate October 13 as National Metastatic Breast Cancer Awareness Day. ${ }^{17}$

Metastatic breast cancer can develop in those who have been adherent to recommended screening and therapy, essentially having "done everything right." While treatments continue to advance and many with metastatic disease are experiencing improved survival rates compared with years past, there is no cure. The fact is, we do not always understand why some patients develop metastatic cancer and some do not, or why some metastatic cancers progress despite modern therapy and some are controlled. This knowledge gap could be closed sooner if all breast cancer advocacy groups devoted more of their time, platform, and resources toward metastatic research efforts. As one advocacy organization asserts in its tagline, these patients are "dying for a cure."18

\section{Male Breast Cancer}

Male breast cancer accounts for approximately $1 \%$ of all breast cancers. This small percentage presents a challenge, as the relative infrequency of breast cancer occurring in men contributes to limited awareness and lack of inclusion in many clinical trials. Men are more likely to be diagnosed at later stages, and their outcomes are poorer compared with women diagnosed at the same stage. Treatment for male breast cancer usually follows established protocols for breast cancer treatment in women, despite lack of evidence in some situations. ${ }^{19,20}$

Despite this disease burden, men are not commonly featured in awareness campaigns, missing an opportunity to educate the public about presenting signs and symptoms, treatment options, and the association of male breast cancer with pathogenic genetic mutations (eg, $B R C A$ mutations). This is slowly changing, in part due to media attention when a male celebrity is diagnosed ${ }^{21}$ and the tireless work of patient advocacy groups. The Male Breast Cancer Coalition series titled "Men Have Breasts Too" features patient stories from men diagnosed with breast cancer, ${ }^{22}$ which can serve as a source of education and support for men diagnosed with what is typically considered a "female" disease.

Inclusion of men in clinical trials is an important and essential step to help determine the best treatment approach for male breast cancer. The U.S. Food and Drug Administration (FDA) has recently recommended that men be included in clinical trials evaluating medications for the treatment of breast cancer, specifically noting that the "FDA does not intend to consider low expected accrual rates of male patients with breast cancer to be a sufficient scientific rationale for excluding them from a clinical trial." ${ }^{23}$ An ongoing international multicenter collaboration should provide important insights into the biologic differences between breast cancer in men and women, as well as draw attention to the unique physical and psychological effects experienced by men diagnosed with and treated for breast cancer. ${ }^{19,24}$

Men must be included in advocacy and awareness campaigns with a focus on presenting symptoms, treatment options, the role of family history and genetic testing, and the unique supportive care needs of men.

\section{Disparities}

Not all patient populations have benefited from improvements in cancer screening, treatment, and outcomes. Disparities exist and may be related to race or ethnicity, socioeconomic status, sexual orientation, gender identity, and other factors. ${ }^{25,26}$ Costs of care, including nonmedical costs such as transportation, may disproportionately affect certain patient populations. ${ }^{27,28}$

Importantly, not all disparities can be adequately explained by imbalanced societal structures, health care barriers and biases, or simple awareness. Breast cancer is less common in Black women compared with White women, but Black women have poorer outcomes, in part due to later stage and younger age at diagnosis, as well as higher likelihood of diagnosis with the triple-negative subtype. Biological differences in breast cancers in Black compared with White women have been identified, although more research is needed to determine the impact of biological versus socioeconomic factors associated with delays in diagnosis and higher mortality rates. ${ }^{29-31}$ 
While there are a growing number of advocacy groups specifically focused on minority patient populations and their unique needs, large national advocacy organizations should take the lead to ensure that their awareness campaigns and support programs also address these issues. The American Society of Clinical Oncology has recently updated its policy statement on cancer disparities and health equity with specific recommendations to promote health equity by focusing on access to highquality care, improving clinical research, and addressing structural barriers. ${ }^{25,26}$

\section{Clinical Trials and Research Funding}

A common theme in discussing those traditionally marginalized by BCAM campaigns is the importance of research and clinical trials. However, less than $10 \%$ of all patients with cancer in the United States are enrolled in a clinical trial as part of their treatment. ${ }^{32}$ There are many barriers to accrual: lack of understanding of the importance and potential benefits of clinical trials; lack of an available trial for a specific cancer type or stage; narrow eligibility criteria; treatment protocols requiring care at a centralized facility that may not be geographically convenient; transportation and other costs; and biases, unconscious or otherwise, on the part of medical teams..$^{32-35}$ Despite efforts to include diverse and representative populations in available trials, these barriers often disproportionately affect those of lower socioeconomic status as well as racial and ethnic minority populations, therefore trial results may not equally apply to all affected with breast cancer. ${ }^{36}$

Another challenge is that national research funding is subject to changes in federal budget and administration priorities. ${ }^{37,38}$ Charlotte Haley's original vision for the peach ribbon was to call attention to lack of research funding, and it has become more important than ever that the general public be aware that pink ribbons and labels do not equal progress. Awareness campaigns that do not emphasize the importance of research will not contribute to meaningful progress.

\section{Pushing Forward}

There is no doubt that spreading breast cancer awareness is still necessary. But awareness that is not partnered with action will not result in progress. Awareness campaigns need to accurately represent all of the faces of breast cancer, address barriers and promote equitable access to care, and emphasize the importance of research. Only then do we have any hope of making a real impact toward ensuring timely diagnosis and care, improving quality of life, and reducing the number of women and men who die from this disease every year.

\section{References}

1. Riggs MJ, Cox Bauer CM, Miller CR, Aden JK, Kamelle SA. Validation of an endometrial tumor diameter model for risk assessment when lymph node mapping fails. J Patient Cent Res Rev. 2020;7:323-8.

2. Sangha R, Bossick A, Su WTK, Coleman C, Chavali N, Wegienka G. A prospective study of patterns of regret in the year after hysterectomy. J Patient Cent Res Rev. 2020;7:329-36.

3. Horter DA, Heslin K, Forgie M, Malloy E, Kram JJ. Dancing during labor: Are women down to boogie? J Patient Cent Res Rev. 2020;7:349-54.

4. Storey S, Cohee A, Von Ah D, et al. Presence and distress of chemotherapy-induced peripheral neuropathy symptoms in upper extremities of younger and older breast cancer survivors. J Patient Cent Res Rev. 2020;7:295-303.

5. Katz MS, Staley AC, Attai DJ. A history of \#BCSM and insights for patient-centered online interaction and engagement. J Patient Cent Res Rev. 2020;7:304-12.

6. Cairo J, Williams L, Bray L, Goetzke K, Perez AC. Evaluation of a mobile health intervention to improve wellness outcomes for breast cancer survivors. J Patient Cent Res Rev. 2020;7:313-22

7. Reddy S, Saxon M, Patel N, et al. Discordance in perceptions of barriers to breast cancer treatment between Hispanic women and their providers. J Patient Cent Res Rev. 2020;7:337-42.

8. Gregory WD, Christie SM, Shell J, Nahhas GJ, Singh M, Mikkelson W. Cole relaxation frequency as a prognostic parameter for breast cancer. $J$ Patient Cent Res Rev. 2020;7:343-8

9. Hendrix K. Peach Corps: Activism: Breast cancer has afflicted her grandmother, sister and daughter, so Charlotte Haley is urging people to wear ribbons to 'wake up' America. Los Angeles Times. Published August 20, 1992; accessed September 6, 2020. https://www.latimes.com/archives/laxpm-1992-08-20-vw-6473-story.html

10. Fernandez SM; thinkbeforeyoupink.org. History of the pink ribbon. Pretty in pink. Accessed August 25, 2020. https:// thinkbeforeyoupink.org/resources/history-of-the-pink-ribbon/

11. Berry LL, Davis SW, Godfrey Flynn A, Landercasper J, Deming KA. Is it time to reconsider the term "cancer survivor"? J Psychosoc Oncol. 2019;37:413-26. Crossref

12. thinkbeforeyoupink.org. 4 questions before you buy pink. Accessed August 25, 2020. https://thinkbeforeyoupink.org/ resources/before-you-buy/

13. Cancer.Net ${ }^{\mathrm{TM}}$. Breast cancer - metastatic: introduction. Page content approved April 2019; accessed September 5, 2020. https://www.cancer.net/cancer-types/breast-cancermetastatic/introduction

14. Waks AG, Winer EP. Breast cancer treatment: a review. JAMA. 2019;321:288-300. Crossref

15. Mariotto AB, Etzioni R, Hurlbert M, Penberthy L, Mayer M. Estimation of the number of women living with metastatic breast cancer in the United States. Cancer Epidemiol Biomarkers Prev. 2017;26:809-15. Crossref

16. American Cancer Society. Breast Cancer Facts \& Figures 2019-2020. American Cancer Society, Inc.; 2019. Accessed September 5, 2020. Available at: https://www.cancer.org/ content/dam/cancer-org/research/cancer-facts-and-statistics/ breast-cancer-facts-and-figures/breast-cancer-facts-andfigures-2019-2020.pdf 
17. Metastatic Breast Cancer Network. History of Metastatic Breast Cancer Day - October 13. Accessed September 5, 2020. http://mbcn.org/history-of-metastatic-breast-cancerday-october-13/

18. METUP.ORG. Home page. Accessed September 6, 2020. http://metup.org/

19. Giordano SH. Breast cancer in men. $N$ Engl $J$ Med. 2018;378:2311-20. Crossref

20. Hassett MJ, Somerfield MR, Baker ER, et al. Management of male breast cancer: ASCO guideline. J Clin Oncol. 2020;38:1849-63. Crossref

21. Taylor DB. Beyoncé's father, Mathew Knowles, on his breast cancer diagnosis. The New York Times. Published October 3, 2019; accessed August 25, 2020. https://www.nytimes. com/2019/10/03/us/mathew-knowles-breast-cancer.html

22. The Male Breast Cancer Coalition. Men have breasts too. Accessed August 25, 2020. https://malebreastcancercoalition. org/men-have-breasts-too/

23. U.S. Food and Drug Administration. Male breast cancer: developing drugs for treatment. Guidance for industry. Accessed August 25, 2020. https://www.fda.gov/regulatoryinformation/search-fda-guidance-documents/male-breastcancer-developing-drugs-treatment

24. Cardoso F, Bartlett JMS, Slaets L, et al. Characterization of male breast cancer: results of the EORTC 10085/TBCRC/ BIG/NABCG International Male Breast Cancer Program. Ann Oncol. 2018;29:405-17. Crossref

25. Patel MI, Lopez AM, Blackstock W, et al. Cancer disparities and health equity: a policy statement from the American Society of Clinical Oncology. J Clin Oncol. 2020;38:3439-48. Crossref

26. Pierce LJ. A time to dig deeper and take meaningful action. J Clin Oncol. 2020;38:3361-2. Crossref

27. Lee A, Shah K, Chino F. Assessment of parking fees at National Cancer Institute-designated cancer treatment centers. JAMA Oncol. 2020;6:1295-7. Crossref

28. Chino F, Peppercorn JM, Rushing C, et al. Out-of-pocket costs, financial distress, and underinsurance in cancer care. JAMA Oncol. 2017:3:1582-4. Crossref

29. Newman LA. Breast cancer disparities: socioeconomic factors versus biology. Ann Surg Oncol. 2017;24:2869-75. Crossref
30. Scott LC, Mobley LR, Kuo TM, Il'yasova D. Update on triple-negative breast cancer disparities for the United States: a population-based study from the United States Cancer Statistics database, 2010 through 2014. Cancer. 2019; 125:3412-7. Crossref

31. Singh M, Konduri SD, Bobustuc GC, Kassam AB, Rovin RA. Racial disparity among women diagnosed with invasive breast cancer in a large integrated health system. $J$ Patient Cent Res Rev. 2018;5:218-28. Crossref

32. Unger JM, Vaidya R, Hershman DL, Minasian LM, Fleury ME. Systematic review and meta-analysis of the magnitude of structural, clinical, and physician and patient barriers to cancer clinical trial participation. J Natl Cancer Inst. 2019;111:245-55. Crossref

33. Cancer Action Network; American Cancer Society. Barriers to patient enrollment in therapeutic clinical trials for cancer. Posted April 11, 2018; accessed August 25, 2020. https:// www.fightcancer.org/policy-resources/clinical-trial-barriers

34. Chino F, Zafar SY. Financial toxicity and equitable access to clinical trials. Am Soc Clin Oncol Educ Book. 2019;39:11-8. Crossref

35. Winkfield KM, Philips JK, Joffe S, Halpern MT, Wollins DS, Moy B. Addressing financial barriers to patient participation in clinical trials: ASCO policy statement. J Clin Oncol. 2018;36:3331-9. Crossref

36. Freedman RA, Ruddy KJ. Who are the patients in our clinical trials for cancer? J Clin Oncol. 2019;37:1519-23. Crossref

37. American Society of Clinical Oncology. Research funding by the National Cancer Institute: from pipeline to patient. Accessed September 5, 2020. https://www.asco.org/sites/ new-www.asco.org/files/content-files/advocacy-and-policy/ images/ASCO-Cancer-Research-Pipeline-Infographic.pdf

38. ASCO in Action. Cancer community and other stakeholders urge \$3 billion NIH funding increase for FY2021: take action. Posted February 18, 2020; accessed September 5, 2020. https:// www.asco.org/practice-policy/policy-issues-statements/ascoin-action/cancer-community-and-other-stakeholders-urge

(C) 2020 Advocate Aurora Health, Inc. 